\title{
Screening for Psychopathology Using the Three Factors Model of the Structure of Psychopathology: A Modified Form of GAIN Short Screener
}

\author{
Ibrahim A. Kira ${ }^{1,2}$, Hanaa Shuwiekh ${ }^{3}$, Justyna Kucharska4 \\ ${ }^{1}$ Center for Cumulative Trauma Studies, Stone Mountain, Georgia, USA \\ ${ }^{2}$ The Center for Stress, Trauma and Resiliency, Georgia State University, Atlanta, Georgia, USA \\ ${ }^{3}$ Fayoum University, Fayoum, Egypt \\ ${ }^{4}$ Queen Mary University of London, London, UK \\ Email:kiraaref@aol.com
}

How to cite this paper: Kira, I. A., Shuwiekh, H., \& Kucharska, J. (2017). Screening for Psychopathology Using the Three Factors Model of the Structure of Psychopathology: A Modified Form of GAIN Short Screener. Psychology, 8, 2410-2427. https://doi.org/10.4236/psych.2017.814152

Received: November 23, 2017

Accepted: December 15, 2017

Published: December 18, 2017

Copyright ( $) 2017$ by authors and Scientific Research Publishing Inc. This work is licensed under the Creative Commons Attribution International License (CC BY 4.0).

http://creativecommons.org/licenses/by/4.0/

(c) (i) Open Access

\begin{abstract}
The goal of this paper is to develop a valid and reliable screening tool for mental health that is based on empirically and conceptually valid structure of psychopathology. Recently several studies of the structure of psychopathology found a general factor and three specific factors: internalizing, externalizing and thought disorder. We adapted the previously validated GAIN Short Screener to include the thought disorder that was not included in its original version and further developed its internalizing subscale. We conducted an exploratory and confirmatory factor analysis of the new adapted measure and produced 20 items screening tool that parsimoniously represents the three factors. The adapted screener and its subscales were found to have good reliability, stability, structural validity in two Egyptian and Polish samples. Additionally, all its subscales significantly correlated with different trauma types and with cumulative trauma, and negatively with self-esteem. The new adapted measure is the first that is based on robust scientific evidence of the structure of psychopathology and can be used in a broad scope of settings.
\end{abstract}

\section{Keywords}

Screening for Mental Health, Structure of Psychopathology, Internalizing, Externalizing, Thought Disorder, Stress and Trauma

\section{Introduction}

There is a lack of valid and reliable screening tool for psychopathology that is 
based on robust conceptual and empirical evidence of the structure of psychopathology. There were no empirically validated conceptual models behind most of the existing measures. Most screening measures for psychopathy targeted either specific disorder or general psychopathology. Most of the measures that screen for general psychopathy either utilized the diagnostic criteria of mental disorder (e.g., Harvard trauma questionnaire) or targeted the general psychopathology in aparticular population (e.g., refugees) (e.g., cumulative trauma disorders in refugees, Kira et al., 2012). World Health Organization WHO (Beusenberg, Orley, \& World Health Organization, 1994) developed a self-reporting questionnaire of 20 questions (SRQ-20) as a screening tool to detect common mental disorders (CMD). Several versions of the Self-Reporting Questionnaire (SRQ) were used in screening and research. SRQ is not based on empirical or theoretical analysis of the structure of psychopathology. It includes only symptoms related to anxiety and depression. The mood, neurotic and psychotic disorders are also common and there is a noticeable overlap of symptoms of depression, anxiety, fatigue, or somatic complaints in CMD. However, different versions added other items that represented psychotic symptoms (e.g., Youngmann et al., 2008). One of the measures that widely used with refugees and torture survivors is Harvard trauma questionnaire (HTQ) (e.g., Mollica et al., 1992). HTQ may be a useful tool for measuring some syndromes, but not designed to be a comprehensive screening tool for psychopathology. The same critique that targeted early SRQ versions applies to HTQ, as it does not measure, for example, dissociation psychosis and other mental health syndromes especially present in multiply traumatized populations (Kira et al., 2012).

Co-morbidity of mental disorders is commonly found in clinical and epidemiological studies (e.g., Kessler, Chiu, Demler, \& Walters, 2005; Angold, Costello, \& Erkanli, 1999). Research suggests the existence of a general psychopathology factor, which is associated with high risk of developing a broad range of internalizing, externalizing and psychotic mental disorders (e.g., Lahey et al., 2012). In one study, a general latent factor based on repeated assessments of psychiatric symptoms over a 20 -year period explained on average $42 \%$ of the disorders variance (Caspi et al., 2014; Carragher, Krueger, Eaton, \& Slade, 2015). In another large multi-ethnic adult sample, a general factor was estimated to explain between $29 \%$ and $67 \%$, depending on the diagnosis (Kim \& Eaton, 2015). The general psychopathology factor was associated with lower IQ, higher negative affectivity, and lower effortful control (Neumann et al., 2016). Importantly, the general psychopathology factor showed a significant Single nucleotide polymorphism (SNP) heritability of 38\% (Neumann et al., 2016). Most of the studies above used DSM oriented scales; however, the general psychopathology factor was also replicated in studies using problem scales/items in general population samples (Laceulle, Vollebergh, \& Ormel, 2015; Murray, Eisner, \& Ribeaud, 2016). These new advances in discovering the component of psychopathology structure gave us an opportunity to develop psychopathology screening tool for 
adult and adolescent from various populations, based on the robust empirically validated conceptual model of psychopathology that represent its three main factors: Internalizing, externalizing and thought disorder. To develop such a measure that represents the three factors, we previously adapted and utilized GAIN- Short Screeners (GAIN-SS) (Dennis, Chan, \& Funk, 2006) in several studies. GAIN-SS was developed initially to screen for psychopathy in adults and adolescent and includes measures for externalizing, internalizing and addiction, but does not add a measure of thought disorder. GAIN-SS is a screener that identifies clients (adults and adolescents) who are likely to have mental health disorders, issues with crime/violence, and issues with substance use. In the first adaptation of the measure, we added items to the internalizing section that are related to posttraumatic stress disorder symptoms. The original version of internalizing subscale did not include different PTSD symptoms. We added a subscale for psychoticism and dissociation using items from psychoticism/dissociation subscale of cumulative trauma disorder scale (Kira et al., 2012). The measure in its initially adapted from included the three primary components of psychopathology: Internalizing, externalizing and thought disorder (psychoticism) (e.g., Caspi et al., 2014; Laceulle, Volleberge, \& Ormel, 2015). The initially adapted measure included 32 items (Internalizing: nine questions, Externalizing and Substance Abuse: 14 items, thought disorder or psychoticism: nine items) (see Appendix 1). The participant is asked to indicate if the behavior (or feeling) happened in the past month (scored 4), or occurred in the last $2-3$ months (scored 3), or in the last 3 - 12 months (scored 2), or the last year or more (scored 1), or never happened (scored 0 ). High scores indicate potentially higher symptoms in these areas.

The authors utilized the version that has been previously adapted in several studies (e.g., Kira, Shuwiekh, \& Bujold-Bugeaud, 2017; Kira, Shuwiekh, Kucharska, Abu-Ras, \& Bujold-Bugeaud, 2017; Kucharska, 2017) and proved to be useful, reliable and valid. The goal was to further develop, refine and evaluate its psychometric properties. Accordingly, we are assessing this previously adapted screener that measure the three factors identified as the specific components of psychopathology to make it a more parsimonious and focused screening tool. The goal is to trim the previously adapted version of the GAIN Short screener. We initially deleted two items from the externalizing subscale to make it more parsimonious. We conducted our current analysis of the left 30 items.

Research Questions

1) Does the adapted version of GAINS screener have adequate reliability and stability?

2) Does it have good construct heuristics being associated with different trauma types and with cumulative trauma, and negatively associated with self-esteem?

3) Does exploratory and confirmatory factor analysis support the structural validity of the three specific factors of internalizing, externalizing and thought 
disorder in two Western (Polish), and non-Western (Egyptian) samples?

\section{Methods}

\subsection{Procedures and Participants}

We utilized data from two samples previously collected that utilized the initially constructed 32 items adapted GAINS S. Screener (see, Kira, Shuwiekh, \& Bujold-Bugeaud, 2017; Kira, Shuwiekh, Kucharska, Abu-Ras, \& Bujold-Bugeaud, 2017; Kucharska, 2017). The following, briefly described the two data sets we utilized in the analysis.

\subsubsection{The First Sample (The Egyptian Sample)}

1) Participants

The current dataset included combined two data sets (one included males and the other females only) and consisted of 523 participants. Participants recruited from the population of Egyptian students taking an undergraduate course who agreed to participate in the study. The sample included students enrolled in varieties of majors (Nursing, Arts \& Humanities, and Physical Education) from South Valley University, Qena, Egypt. Five hundred twenty-three students participated in the study. The combined sample included $61 \%$ females. Participants were from all different class levels: freshmen $(51.5 \%, \mathrm{n}=104)$, sophomores $(24 \%, \mathrm{n}=49)$, juniors $(24 \%, \mathrm{n}=49)$, and seniors $(0.5 \%, \mathrm{n}=2)$. The majority of the respondents were under the age of $20(84.5 \%, \mathrm{n}=171)$, and $14.7 \%$. The rest (1.5\%) was the age of $22-23$. Age ranged from 18 to 23, with a mean of 19.33 and SD of 1.20 . For religion, $96.2 \%$ were Muslims, and $3.8 \%$ were Christians. While only $28.4 \%$ came from urban areas, $71.6 \%$ came or reside in rural areas.

\section{2) Procedure}

Research associates administered the questionnaire to participants in Arabic from September to November of 2015. While the questionnaires administered to males and females were different, all have the same measures utilized in the current analysis and were combined in one data set. The participation was voluntary. Each participant was informed about the general goals of the study and signed informed consent to participate. Each person took between 40 - $50 \mathrm{mi}$ nutes to complete the questionnaire. The Institution Review Board of authors' institution approved the research as part of a cross-cultural study of gender relations among college students.

\subsubsection{The Second Sample (The Polish Sample)}

\section{1) Participants}

The Polish dataset included combined two data sets (one included males and the other females only) of 467 college students from two Polish cities: Warsaw and Wrocław. Females were 59.3\% of the sample. Study assistants recruited participants via opportunity sampling at university campuses during the breaks between classes. The age range in the sample is $18-34, \mathrm{M}=22.39, \mathrm{SD}=2.81$. All participants were residents of one of the cities and enrolled as students at the 
time of the data collection. Participants signed an informed consent and received no compensation for their participation in the study.

2) Procedure

Research team administered the questionnaire in Polish, from January to February 2016. Each participant informed about the general goals of the study and signed informed consent to participate. Each person took between 40 - 50 minutes to complete the questionnaire. While the questionnaires administered to males and females were different, all have the same measures utilized in the current analysis and were combined in one data set. The two data sets included the same measures that we will describe in the following section.

\subsubsection{The Measures Used in the Two Studies}

In addition to the modified version of the GAINS screener, the used measures included the following measures:

The Cumulative Trauma Scale CTS-S (short form) is a measure based on the development-based trauma framework (DBTF) (e.g., Kira, 2001; Kira, Ashby et al., 2013; Kira, Fawzi, \& Fawzi, 2013; Kira, Lewandowski et al., 2008; Kira, Lewandoski, Chiodo, \& Ibrahim, 2014; Kira, Omidy, \& Ashby, 2014). DBTF identifies and measures different dimensions of individual development that may be affected by stress and traumatic stress (i.e., attachment, personal, collective and role identities, and interdependence). The CTS-S is a 32-item instrument that measures cumulative trauma regarding the occurrence, frequency, type, and negative and positive appraisals. The test is intended to measure at least seven major trauma types. They include collective identity trauma ( 3 items), personal identity trauma (6 items), survival trauma (6 items), attachment trauma (2 items), secondary trauma ( 7 items), achievement traumas ( 2 items) and gender discrimination ( 2 items). Collective identity trauma includes trauma related to exposure to war and torture and discrimination based on race, ethnicity, or national origin. Personal identity trauma includes trauma related to sexual abuse, rape, incest, and being robbed. Attachment trauma comprises abandonment by parents. Survival trauma includes car accidents, life-threatening illnesses, and natural disasters. Achievement or role identity trauma is intended to measure traumatic stressors related to attainment of life goals like success in school or business. Secondary trauma includes trauma related to having witnessed a traumatic event occurring to another individual or group and affecting social interdependence. Gender discrimination includes gender discrimination by parents (family) and gender discrimination by society and institutions. Gender discrimination items are worded to apply to both genders. In response to each item on the measure, participants are instructed to indicate their experience with a traumatic event on a 5 -point Likert-type scale ( $0=$ never; $4=$ many times). If a participant denotes that she/he has experienced the traumatic event, then he/she is asked to describe her/his appraisal of its effect on a 7-point Likert-type scale (1 $=$ extremely positive; $7=$ extremely negative). CTS-S includes two general subscales for cumulative trauma dose: occurrence and frequency of experience, and 
two appraisal subscales: negative and positive appraisal. Four subscales for each of the trauma types can be obtained.

The CTS-S has shown adequate internal consistency $(\alpha=.85$; Kira et al., 2008, Kira, Fawzi et al., 2013). Evidence of the instrument's predictive validity includes cumulative trauma significantly predicting post-traumatic stress disorder ( $\mathrm{r}$ $=.54, \mathrm{p}<.001)$, cumulative trauma-related disorders $(\mathrm{r}=.24, \mathrm{p}<.001)$, and poor health $(\mathrm{r}=.37, \mathrm{p}<.001$; Kira et al., 2008). CTS-S has also shown divergent validity: It was significantly negatively correlated with sociocultural adjustment $(\mathrm{r}=-.25, \mathrm{p}<.001)$ and futuristic orientation $(\mathrm{r}=-.37, \mathrm{p}<.001)$. Research used CTS- with a variety of clinical and community samples of adults and adolescents from numerous sociocultural groups. It had been shown to possess adequate reliability (with an alpha ranging between .80 and .92), good construct validity (e.g., Kira et al., 2008; Kira, Lewandowski, Somers, Yoon, \& Chiodo, 2012; Kira, Smith, Lewandowski, \& Templin, 2010), and validity across different cultural and clinical groups, including American Indians, Mayans, Palestinians, Egyptians, refugees, and torture survivors from 32 countries (e.g., Kira, Ashby, Odenat, \& Lewandowski, 2013; Kira, Fawzi et al., 2013; Kira, Omidy, \& Ashby, 2014). Several studies used the measure as a comprehensive measure of stress and trauma (e.g., Gillespie \& Gates, 2013; Head, Singh, \& Bugg, 2012; Millender, 2013; Omidy, 2012) and has been found to have good reliability and predictive validity. Test-retest using an independent sample of 35 males with four weeks interval yielded excellent stability coefficients (.995 for cumulative trauma frequency, and .997 for cumulative trauma appraisal).

The alpha for the scale of cumulative trauma occurrence was .88 in the Egyptian data and .91 in the Polish data. The measure was used to test if the adapted GAINShort Screener and its sub-tests will be significantly associated with different trauma types.

The Rosenberg self-esteem scale (RSES) is a 10-item scale that measures global self-esteem (Rosenberg, 2015). Each item rated on a 4-point Likert-type scale from strongly agree to disagree strongly and scored from 0 to 3 . The scale divided into five positively worded and five negatively worded statements. The RSES has been translated and adapted to various languages including Arabic. Rosenberg reported good psychometrics for the scale and its reliability ranging from .85 to .88 . In previous Arabic samples, alpha was .75. Test-retest using an independent sample of 35 males with four weeks interval yielded excellent stability coefficient of .983. In the Egyptian study, its alpha was .72, In the Polish study, its alpha reliability was .78. The measure was used to test if the adapted GAINShort Screener and its sub-tests will be negatively associated with self-esteem.

\subsubsection{Translation into Polish Procedures}

Self-esteem scale: the Polish adaptation, was published in 2008 (Dzwonkowska, Lachowicz-Tabaczek, \& Laguna, 2008), the scale has good reliability and validity and is widely used in Poland. For the other scales: first certified Polish transla- 
tors translated the tools into Polish, then were back-translated into English, a third expert compared the initial and final English versions. No significant differences found in the case of discrimination scales and authoritarianism scale. Minor differences found in the cumulative trauma scale and Gain externalizing scale, but the third expert decided that the items have the same meaning as the words used have a similar semantic field.

\subsubsection{Translation into Arabic Procedures}

Some of these measures have been previously translated into Arabic and proved to have adequate reliability and validity in Arabic clients in previous studies, as will be briefly described when introducing them in the measures section. We translated the other measures (modified GAIN, and F scale) into Arabic. The committee that translated the measures consisted of three bilingual professionals who conducted the forward translation and two different bilingual professionals who contributed to the reverse translation. The translations compared, and the differences discussed until a consensus reached on the final version by the committee.

\subsubsection{Statistical Analysis Strategy}

The data were analyzed utilizing IBM-SPSS 22 and Amos 22 software. We split the Egyptian sample into two sub-samples $(\mathrm{N}=261$ each). We conducted exploratory factor analysis (Principal axis factoring method) of the Adapted GAINShort screening items in the first Egyptian sub-sample. We conducted exploratory (on the first sub-sample) and confirmatory factor analysis (on the second sub-sample). Because internalizing, externalizing and thought disorder are assumed to be correlated with a higher second-order factor, we conducted an oblique rotation. We used the scree test (Cattell, 1966) and parallel analysis (O'Connor, 2000) to help determine the number of factors. Confirmatory factor analysis was conducted on the resulted in three factors. Following Byrne's (2012) recommendations, the criteria for good model fit were a non-significant $\left(\chi^{2}\right)$, $(\chi 2 /$ d.f. $>2)$, comparative fit index $(\mathrm{CFI})$ values $>0.90$, and root-mean-square error of approximation (RMSEA) values $<0.06$. We investigated the reliability of the sub-scales with the Cronbach's alpha. To test its predictive validity, we conducted a zero-order correlation to explore the linear relationships between the measured constructs.

\section{Results}

\subsection{Reliability}

In the Egyptian study, alpha reliability for internalizing was $.84, .88$ for externalizing and addiction, and .93 for psychoticism. In the Polishes study alpha reliability for internalizing was .68 , and .81 for externalizing and addiction, and .78 for psychoticism. Test-retest using an independent sample of 35 Egyptian college students with four weeks interval yielded excellent stability coefficients (.970 for internalizing, .908 for externalizing, .923 for addiction, .915 for combined exter- 
nalizing and addiction.

\subsection{Correlations}

Externalizing, Internalizing, and thought disorder subscales correlated significantly with all trauma types and with cumulative traumas. All the three subscales correlated negatively with self-esteem. The three subscales were highly correlated. Table 1 provides the zero-order correlations between the mentioned variables in the Egyptian sample. Similar correlations between the three subscales and cumulative trauma, different trauma types were found in the Polish sample. The correlation results provide initial evidence of predictive validity and the Construct Heuristics of the subscales.

\subsection{Structural Validity}

Exploratory factor analysis of both the Egyptian sub-sample and the Polish sample yielded three factors with all items loaded significantly on the first factor (before rotation) which may validate the one-factor solution of psychopathology obtained in previous studies. The Oblimin rotation produced three clear-cut factors that represented the three constructs (thought disorder, internalizing and externalizing (Table 2, see also Appendix 1). The three factors accounted for $48.29 \%$ of the variance. The first factor loaded on thought disorder items and accounted for $33.67 \%$ of the variance. The second factor loaded on internalizing items and accounted for $10.06 \%$ of the variance. The third factor loaded on externalizing items and suicidality and accounted for $4.56 \%$ of the variance. We deleted the items that have less than .40 loadings as well as those that have cross-loading (10 items), and reanalyzed the remaining 20 items. The results indicated a clean three factors solution with a different order (Table 3, see also

Table 1. Zero order correlations between the modified GAINS' subscales, self-esteem and different trauma types in the Egyptian sample.

\begin{tabular}{|c|c|c|c|c|c|c|c|c|c|c|c|}
\hline Variables & 1 & 2 & 3 & 4 & 5 & 6 & 7 & 8 & 9 & 10 & 11 \\
\hline 1) Externalizing & 1 & & & & & & & & & & \\
\hline 2) Psychoticism & $.65^{\star \star \star}$ & 1 & & & & & & & & & \\
\hline 3) Internalization & $.63^{* * *}$ & $.49^{* * *}$ & 1 & & & & & & & & \\
\hline 4) Self-Esteem & $-.20^{* * *}$ & $-.18^{* * *}$ & $-.26^{* * *}$ & 1 & & & & & & & \\
\hline 5) Secondary Trauma & $.26^{* * *}$ & $.24^{* * *}$ & $.25^{* * *}$ & $-.17^{\star * *}$ & 1 & & & & & & \\
\hline 6) Physical identity Traumas & $.23^{* * *}$ & $.23^{* * *}$ & $.26^{* * *}$ & $-.14^{* *}$ & $.50^{* *}$ & 1 & & & & & \\
\hline 7) Role Identity Traumas & $.22^{* * *}$ & $.18^{* * *}$ & $.22^{* * *}$ & $-.19^{* * *}$ & $.33^{* * *}$ & $.21^{* * *}$ & 1 & & & & \\
\hline 8) Attachment Traumas & $.24^{* * *}$ & $.17^{* * *}$ & $.23^{* * *}$ & $-.11^{*}$ & $.39^{* * *}$ & $.21^{* * *}$ & $.20^{* * *}$ & 1 & & & \\
\hline 9) Social (Collective) Identity trauma & $.19^{* * *}$ & $.14^{* * *}$ & $.32^{* * *}$ & $-.10^{*}$ & $.31^{* * *}$ & $.25^{* * *}$ & $.29^{* * *}$ & $.42^{* * *}$ & 1 & & \\
\hline 10) Personal Identity Traumas & $.39^{* * *}$ & $.32^{* * *}$ & $.39^{* * *}$ & $-.21^{* * *}$ & $.46^{* * *}$ & $.40^{* * *}$ & $.38^{* * *}$ & $.49^{* * *}$ & $.48^{* * *}$ & 1 & \\
\hline 11) Cumulative Trauma Occurrence & $.40^{* * *}$ & $.35^{* * *}$ & $.41^{* * *}$ & $-.24^{* * *}$ & $.76^{* * *}$ & $.65^{* * *}$ & $.51^{* * *}$ & $.59^{* * *}$ & $.61^{* * *}$ & $.81^{* * *}$ & 1 \\
\hline
\end{tabular}

Note. ${ }^{*} \mathrm{p}<.05,{ }^{* *} \mathrm{p}<.01,{ }^{* * *} \mathrm{p}<.001$. 
Table 2. Factor structure of the modified GAIN-30 screener in the Egyptian sub-sample.

\begin{tabular}{|c|c|c|c|}
\hline & \multicolumn{3}{|c|}{ Factor } \\
\hline & 1 & 2 & 3 \\
\hline 1. Felt as if you are almost two different people? & .669 & -.004 & -.055 \\
\hline 2. Felt that you do not have enough control over your responses and reactions & .633 & .062 & -.072 \\
\hline 3. Felt apathetic, with no emotion & .572 & .077 & .044 \\
\hline 4. Get irritated, to the extent you do not care about safety & .535 & .120 & .046 \\
\hline 5. Felt you are in two or more different places in the same time & .532 & -.078 & .225 \\
\hline 6. Felt people/ enemies are following you any place you go & .517 & -.091 & .296 \\
\hline 7. Fail to respect those who may represent authority & .472 & .023 & .189 \\
\hline 8. Lied or conned to get things you wanted or to avoid having to do something & .435 & .122 & .106 \\
\hline 9. Seeing or hearing things that no one else could see or hear & .412 & -.007 & .333 \\
\hline 10. Lost temper & .388 & .334 & -.151 \\
\hline 11. Feeling that someone else could read or control your thoughts & .366 & .074 & .342 \\
\hline 12. Had a hard time listening to instructions at school, work, or home & .323 & .274 & .032 \\
\hline 13. Had a hard time waiting for your turn & .311 & .310 & .113 \\
\hline 14. Feeling very anxious, nervous, tense, scared, panicked, or like something bad was going to happen & -.122 & .676 & -.023 \\
\hline 15. Sleep trouble, such as bad dreams, sleeping restlessly, or falling asleep during the day) & -.086 & .668 & .050 \\
\hline 16. Becoming very distressed and upset when something reminded you of the past & .016 & .611 & -.039 \\
\hline 17. Trying to avoid reminders of painful past events & .089 & .570 & .044 \\
\hline 18. Feeling very trapped, lonely, sad, blue, depressed, or hopeless about the future & .007 & .472 & .076 \\
\hline 19. Having unexpected or disturbing memories & .168 & .448 & .148 \\
\hline 20. Feeling out of touch with surrounding & .273 & .396 & .036 \\
\hline 21. Easily irritated. & .325 & .393 & -.131 \\
\hline 22. Jumping or being very frightened by sudden loud noises & .159 & .355 & .099 \\
\hline $\begin{array}{l}\text { 23. You spent a lot of time either getting alcohol or other drugs, using alcohol or other drugs, } \\
\text { or recovering from the effects of alcohol or other drugs (e.g., feeling sick) }\end{array}$ & -.125 & .069 & .926 \\
\hline $\begin{array}{l}\text { 24. Your use of alcohol or other drugs caused you to give up or reduce your involvement } \\
\text { in activities at work, school, home, or social events? }\end{array}$ & -.014 & -.012 & .882 \\
\hline $\begin{array}{l}\text { 25. You kept using alcohol or other drugs even though it was causing social problems, } \\
\text { leading to fights, or getting you into trouble with other people }\end{array}$ & -.083 & .035 & .860 \\
\hline $\begin{array}{l}\text { 26. You had withdrawal problems from alcohol or other drugs like shaky hands, throwing up, } \\
\text { having trouble sitting still or sleeping, or you used any alcohol or other drugs to stop being sick } \\
\text { or avoid withdrawal problems }\end{array}$ & .100 & -.032 & .719 \\
\hline 27. Were a bully or threatened other people. & .101 & .082 & .635 \\
\hline 28. Thinking about hurting self, ending your life or committing suicide & .128 & .192 & .465 \\
\hline 29. Took something from a store without paying for it? & .298 & -.017 & .458 \\
\hline 30. Started physical fights with other people & .365 & .002 & .395 \\
\hline
\end{tabular}

Note: Bolded items are either have loadings less than .4 on the factor, or have cross-loading and were deleted in the second-factor analysis. 
Table 3. Factor structure of the modified GAIN-20 screener in the Egyptian sub-sample.

\begin{tabular}{|c|c|c|c|c|}
\hline & \multirow{2}{*}{ Items } & \multicolumn{3}{|c|}{ Factor } \\
\hline & & 1 & 2 & 3 \\
\hline 1. & $\begin{array}{l}\text { You spent a lot of time either getting alcohol or other drugs, using alcohol or other drugs } \\
\text { or recovering from the effects of alcohol or other drugs (e.g., feeling sick) }\end{array}$ & .946 & .027 & .118 \\
\hline 2. & $\begin{array}{l}\text { Your use of alcohol or other drugs caused you to give up or reduce your involvement in } \\
\text { activities at work, school, home, or social events? }\end{array}$ & .886 & -.043 & -.008 \\
\hline 3. & $\begin{array}{l}\text { You kept using alcohol or other drugs even though it was causing social problems, leading } \\
\text { to fights, or getting you into trouble with other people }\end{array}$ & .871 & .002 & .077 \\
\hline 4. & $\begin{array}{l}\text { You had withdrawal problems from alcohol or other drugs like shaky hands, throwing up, } \\
\text { having trouble sitting still or sleeping, or you used any alcohol or other drugs to stop } \\
\text { being sick or avoid withdrawal problems }\end{array}$ & .742 & -.055 & -.075 \\
\hline 5. & Were a bully or threatened other people & .639 & .108 & -.056 \\
\hline 6. & Thinking about hurting self, ending your life or committing suicide & .451 & .193 & -.142 \\
\hline 7. & Took something from a store without paying for it? & .443 & .009 & -.289 \\
\hline 8. & Feeling very anxious, nervous, tense, scared, panicked, or like something bad was going to happen & -.040 & .678 & .099 \\
\hline 9. & Sleep trouble, such as bad dreams, sleeping restlessly, or falling asleep during the day) & .033 & .639 & .046 \\
\hline 10. & Becoming very distressed and upset when something reminded you of the past & -.052 & .592 & -.058 \\
\hline 11. & Trying to avoid reminders of painful past events & .000 & .535 & -.179 \\
\hline 12. & Feeling very trapped, lonely, sad, blue, depressed, or hopeless about the future & .057 & .494 & -.020 \\
\hline 13. & Having unexpected or disturbing memories & .123 & .447 & -.199 \\
\hline 14. & Felt as if you are almost two different people? & -.089 & .008 & -.712 \\
\hline 15. & Felt that you do not have enough control over your responses and reactions & -.078 & .078 & -.648 \\
\hline 16. & Felt apathetic, with no emotion & .010 & .079 & -.622 \\
\hline 17. & Felt people/enemies are following you any place you go & .278 & -.069 & -.521 \\
\hline 18. & Felt you are in two or more different places in the same time & .204 & -.020 & -.512 \\
\hline 19. & Get irritated, to the extent you do not care about safety & .093 & .153 & -.428 \\
\hline 20. & Seeing or hearing things that no one else could see or hear & .340 & -.004 & -.394 \\
\hline
\end{tabular}

Note: Bolded numbers indicated the significant loadings on each factor.

Appendix 2). The analysis yielded three factors accounted for $54.64 \%$ of the variance. In this analysis the first factor included the items related to externalizing and accounted for $35.89 \%$ of the variance. The second factor included the items related to internalizing and accounted for $12.22 \%$ of the variance. The third factor included the items related to thought disorder and accounted for $6.54 \%$ of the variance.

Additionally, we conducted confirmatory factor analysis on the second Egyptian sample and the Polish sample. For the Egyptian sample, the three factors, twenty items structure fitted adequately (Chi Square $=322.117$, d.f. $=159, \mathrm{p}$ $=.000 . \mathrm{CFI}=.932$, RMSEA $=.063)$. Figure 1 includes the results of the confirmatory factor analysis for GAIN-20 Short Screener in The Egyptian sample. 


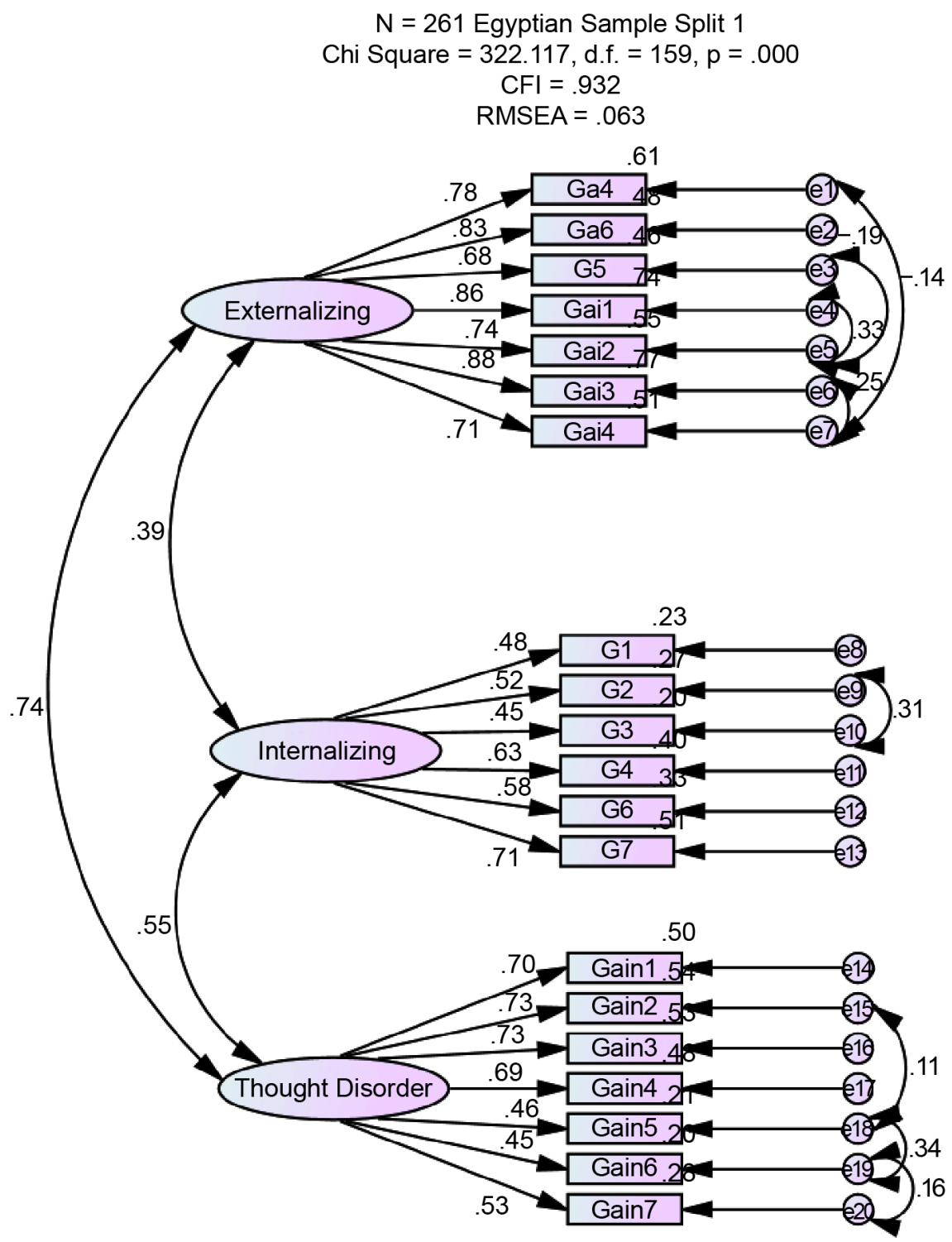

Figure 1. Confirmatory factor analysis for GAIN-20 short screener in the Egyptian sample.

The confirmatory factor analysis using the Polish sample did not fit adequately in the initial analysis. However, the modification indices strongly suggested moving the suicidality item from externalizing items to internalizing items. Conducting this modification, the model fitted well (Chi Square $=451.390$, d.f. $=$ $154, p=.000 . \mathrm{CFI}=.910, \mathrm{RMSEA}=.064)$. Suicidality was significantly correlated with internalizing, externalizing and thought disorder with different strengths in both samples.

\section{Conclusion and Future Directions}

We conclude that the modified GAIN-20 is a structurally valid tool for screening of mental health based on the rigor scientific evidence of the structure of psychopathology. The measure subscales have good reliability and stability in both 
Western and non-Western populations. The goal of this study was to adapt the GAIN Short Screener to measure the three factors that were found in the scientific studies of the structure of psychopathology. The objective was to establish a parsimonious screening tool that may be used to screen for psychopathology in adults and adolescents. We emphasized that the significance of current study lies in the fact that it is the first that provided a tool for mental health screening that is based on the scientific evidence of the structure of psychopathology. The suggested 20 items tool can be utilized cross-culturally and with refugee, minority as well as with mainstream populations. It is not a diagnostic tool but can give the clinical impression a further thorough assessment for the individual who may have a high score in either dimension. Future studies should investigate and establish clinical cut-off points for each factor that may have warranted further evaluation. The problem whether the suicidality item belongs to externalizing or internalizing subscales is interesting. Suicidality is significantly correlated to externalizing, internalizing and thought disorder. Future studies should investigate further the position of suicidality. Suicidality items are clinically important for screening of psychopathology and cannot be deleted for psychometric reasons.

\section{Limitations}

While the current study was an important first step, it has several limitations. For example, the fact that different traumatic stressors significantly correlated with the three subscales does not provide specific predictive validity information of the subscales. To establish their predictive validity, clinical samples should be used. Our samples were college students and it was difficult to establish the predictive validity of the sub-scales using non-clinical samples. Additionally, the externalizing subscales can be reconstructed to include more diverse items to be tested in future studies. The current study is an initial step in devising more accurate screening tool based on the scientific evidence of the structure of psychopathology. An expanded well-funded study may be needed to develop it further to increase the representativeness of its items of all aspects of psychopathology and to establish it as the standard screening measure for psychopathology in the field. Regardless, the modified GAIN-20 screener, in its current form is a valid and reliable tool to screen for psychopathology based on the rigor scientific evidence of its structure.

\section{References}

Angold, A., Costello, E. J., \& Erkanli, A. (1999). Comorbidity. Journal of Child Psychology and Psychiatry, 40, 57-87. https://doi.org/10.1111/1469-7610.00424

Beusenberg, M., Orley, J. H., \& World Health Organization (1994). A User's Guide to the Self Reporting Questionnaire (SRQ). Geneva: WHO.

Byrne, B. M. (2012). Structural Equation Modeling with Mplus: Basic Concepts, Applications, and Programming. New York, NY: Routledge Academic.

Carragher, N., Krueger, R. F., Eaton, N. R., \& Slade, T. (2015). Disorders without Borders: Current and Future Directions in the Meta-Structure of Mental Disorders. Social Psy- 
chiatry and Psychiatric Epidemiology, 50, 339-350.

https://doi.org/10.1007/s00127-014-1004-Z

Caspi, A., Houts, R. M., Belsky, D. W., Goldman-Mellor, S. J., Harrington, H., Israel, S., \& Moffitt, T. E. (2014). The p Factor One General Psychopathology Factor in the Structure of Psychiatric Disorders. Clinical Psychological Science, 2, 119-137. https://doi.org/10.1177/2167702613497473

Cattell, R. B. (1966). The Scree Test for the Number of Factors. Multivariate Behavioral Research, 1, 245-276. https://doi.org/10.1207/s15327906mbr0102_10

Dennis, M. L., Chan, Y. F., \& Funk, R. R. (2006). Development and Validation of the GAIN Short Screener (GSS) for Internalizing, Externalizing and Substance Use Disorders and Crime/Violence Problems among Adolescents and Adults. The American Journal on Addictions, 15, 80-91. https://doi.org/10.1080/10550490601006055

Dzwonkowska, I., Lachowicz-Tabaczek, K., \& Łaguna, M. (2008). Self-Esteem and Its Measurement. Polish Adaptation of M. Rosenberg's SES Scale. Textbook.

Gillespie, G. L., \& Gates, D. M. (2013). Using Proactive Coping to Manage the Stress of Trauma Patient Care. Journal of Trauma Nursing, 20, 44-50. https://doi.org/10.1097/JTN.0b013e318286608e

Head, D., Singh, T., \& Bugg, J. M. (2012). The Moderating Role of Exercise on Stress-Related Effects on the Hippocampus and Memory in Later Adulthood. Neuropsychology, 26, 133-143. https://doi.org/10.1037/a0027108

Kessler, R. C., Chiu, W. T., Demler, O., \& Walters, E. E. (2005) Prevalence, Severity, and Comorbidity of 12-Month DSM-IV Disorders in the National Comorbidity Survey Replication. Archives of General Psychiatry, 62, 617-627. https://doi.org/10.1001/archpsyc.62.6.617

Kim, H., \& Eaton, N. R. (2015). The Hierarchical Structure of Common Mental Disorders: Connecting Multiple Levels of Comorbidity, Bifactor Models, and Predictive Validity. Journal of Abnormal Psychology, 124, 1064-1078. https://doi.org/10.1037/abn0000113

Kira, I. (2001). Taxonomy of Trauma and Trauma Assessment. Traumatology, 2, 1-14. https://doi.org/10.1177/153476560100700202

Kira, I. (2010). Etiology and Treatments of Post-Cumulative Traumatic Stress Disorders in Different Cultures. Traumatology: An International Journal, 16, 128-141. https://doi.org/10.1177/1534765610365914

Kira, I., Ashby, J. S., Lewandowski, L., Alawneh, A. N., Mohanesh, J., \& Odenat, L. (2013). Advances in Continuous Traumatic Stress Theory: Traumatogenic Dynamics and Consequences of Intergroup Conflict: The Palestinian Adolescents Case. Psychology, 4, 396-409. https://doi.org/10.4236/psych.2013.44057

Kira, I. A., Ashby, J., S., Odenat, L., \& Lewandowski, L. (2013). The Mental Health Effects of Torture Trauma and Its Severity: A Replication and Extension. Psychology, 4, 472-482. https://doi.org/10.4236/psych.2013.45067

Kira, I., Fawzi, M., \& Fawzi, M. (2013). The Dynamics of Cumulative Trauma and Trauma Types in Adults Patients with Psychiatric Disorders: Two Cross-Cultural Studies. Traumatology: An International Journal, 19, 179-195. https://doi.org/10.1177/1534765612459892

Kira, I., Lewandowski, L., Chiodo, L., \& Ibrahim, A. (2014). Advances in Systemic Trauma Theory: Traumatogenic Dynamics and Consequences of Backlash as a Multi-Systemic Trauma on Iraqi Refugee Muslim Adolescents. Psychology, 5, 389-412. https://doi.org/10.4236/psych.2014.55050 
Kira, I., Lewandowski, L., Templin, T., Ramaswamy, V., Ozkan, B., \& Mohanesh, J. (2008). Measuring Cumulative Trauma Dose, Types and Profiles using a Development-Based Taxonomy of Trauma. Traumatology: International Journal, 14, 62-87. https://doi.org/10.1177/1534765608319324

Kira, I. A., Omidy, A. Z., \& Ashby, J. S. (2014). Cumulative Trauma, Appraisal, and Coping in Palestinian and American Indian Adults: Two Cross-Cultural Studies. Traumatology: An International Journal, 20, 119-133. https://doi.org/10.1037/h0099397

Kira, I., Templin, T., Lewandowski, L., Ashby, J. S., Oladele, A., \& Odenat, L. (2012). Cumulative Trauma Disorder Scale: Two Studies. Psychology, 3, 643-656. https://doi.org/10.4236/psych.2012.39099

Kira, I., Shuwiekh, H., \& Bujold-Bugeaud (2017). Toward Identifying the Etiologies of Gender Differences in Authoritarianism and Mental Health: An Egyptian Study. Peace and Conflict: Journal of Peace Psychology, 23, 183-188.

https://doi.org/10.1037/pac0000206

Kira, I., Shuwiekh, H., Kucharska, J., Abu-Ras, W., \& Bujold-Bugeaud, M. (2017). The Dynamics Underlying the Negative Mental Health Effects of Gender Discrimination in Two Samples: Poland and Egypt. Current Psychology, 1-15.

https://doi.org/10.1007/s12144-017-9730-5

Kucharska, J. (2017). Sex Differences in the Appraisal of Traumatic Events and Psychopathology. Psychological Trauma: Theory, Research, Practice, and Policy, 9, 575-582. https://doi.org/10.1037/tra0000244

Laceulle, O. M., Vollebergh, W. A. M., \& Ormel, J. (2015). The Structure of Psychopathology in Adolescence: Replication of a General Psychopathology Factor in the TRAILS Study. Clinical Psychological Science, 3, 850-860. https://doi.org/10.1177/2167702614560750

Lahey, B. B., Applegate, B., Hakes, J. K., Zald, D. H., Hariri, A. R., \& Rathouz, P. J. (2012). Is There a General Factor of Prevalent Psychopathology during Adulthood? Journal of Abnormal Psychology, 121, 971-977. https://doi.org/10.1037/a0028355

Millender, E. I. (2013). Cumulative Trauma among Adult Mayas Living in Southeast Florida. Florida Atlantic University.

Mollica, R. F., Caspi-Yavin, Y., Bollini, P., Truong, T., Tor, S., \& Lavelle, J. (1992). The Harvard Trauma Questionnaire: Validating a Cross-Cultural Instrument for Measuring Torture, Trauma, and Posttraumatic Stress Disorder in Indochinese Refugees. The Journal of Nervous and Mental Disease, 180, 111-116. https://doi.org/10.1097/00005053-199202000-00008

Murray, A. L., Eisner, M., \& Ribeaud, D. (2016). The Development of the General Factor of Psychopathology "p Factor" through Childhood and Adolescence. Journal of $A b$ normal Child Psychology, 44, 1573-1586. https://doi.org/10.1007/s10802-016-0132-1

Neumann, A., Pappa, I., Lahey, B. B., Verhulst, F. C., Medina-Gomez, C., Jaddoe, V. W., Tiemeier, H. et al. (2016). Single Nucleotide Polymorphism Heritability of a General Psychopathology Factor in Children. Journal of the American Academy of Child \& Adolescent Psychiatry, 55, 1038-1045. https://doi.org/10.1016/j.jaac.2016.09.498

O'Connor, B. P. (2000). SPSS and SAS Programs for Determining the Number of Components using Parallel Analysis and Velicer's MAP Test. Behavior Research Methods, Instruments, \& Computers, 32, 396-402. https://doi.org/10.3758/BF03200807

Omidy, Nael, A. Z. O. (2012). The Influence of Cumulative Trauma, Binge Eating, and Coping Styles on the General Health of American Indians. Oklahoma State University. 
Rosenberg, M. (2015). Society and the Adolescent Self-Image. Princeton: Princeton University Press.

Youngmann, R., Zilber, N., Workneh, F., \& Giel, R. (2008). Adapting the SRQ for Ethiopian Populations: A Culturally-Sensitive Psychiatric Screening Instrument. Trans-Cultural Psychiatry, 45, 566-589. https://doi.org/10.1177/1363461508100783 


\section{Appendix 1}

Adapted GAIN Short Screener (A-GAIN-SS-30) for Internalizing, Externalizing, and Thought Disorder (The first modified version).

The following questions are about common psychological, behavioral, and personal problems. These problems are considered significant when you have them for two or more weeks when they keep coming back, when they stop you from meeting your responsibilities, or when they make you feel like you can't go on.

After each of the following questions, please tell us the last time, if ever, you had the problem by answering whether

- It was in the past week (5)

- It was in the past month (4),

- 2 to 3 months ago (3),

- 4 to 12 months ago (2),

- 1 or more years ago (1),

- Never (0).

1. When was the last time that you had significant problems with:

a) Feeling very trapped, lonely, sad, blue, depressed, or hopeless about the future? 43210

b) Sleep trouble, such as bad dreams, sleeping restlessly, or falling asleep during the day? 432210

c) Feeling very anxious, nervous, tense, scared, panicked, or like something bad was going to happen? 43210

d) Becoming very distressed and upset when something reminded you of the past? 43210

e) Thinking about hurting self, ending your life or committing suicide? 43210

f) Having unexpected or disturbing memories? 43210

g) Trying to avoid reminders of painful past events? 43210

h) Jumping or being very frightened by sudden loud noises? 43210

i) Feeling out of touch with surrounding? 43210

2. When was the last time that you did the following things two or more times?

a) Lied or conned to get things you wanted or to avoid having to do something 432210

b) Had a hard time listening to instructions at school, work, or home 43210

c) Had a hard time waiting for your turn 43210

d) Bullied or threatened other people 43210

e) Started physical fights with other people 43210

f) Took something from a store without paying for it? 43210

g) Lost temper 43210

h) Easily irritated 432210

i) Failed to respect those who may represent authority 43210

j) Get irritated, to the extent you do not care about safety 43210

3. When was the last time that:

a) you spent a lot of time either getting alcohol or other drugs, using alcohol or other drugs or recovering from the effects of alcohol or other drugs (e.g., feeling sick)? 43210 
b) You kept using alcohol or other drugs even though it was causing social problems, leading to fights, or getting you into trouble with other people? 43210

c) Your use of alcohol or other drugs caused you to give up or reduce your involvement in activities at work, school, home, or social events? 43210

d) you had withdrawal problems from alcohol or other drugs like shaky hands, throwing up, having trouble sitting still or sleeping, or you used any alcohol or other drugs to stop being sick or avoid withdrawal problems? 43210

4. When was the last time that you:

a) seeing or hearing things that no one else could see or hear 43210

b) feeling that someone else could read or control your thoughts? 43210

c) Felt people/enemies are following you any place you go? 43210

d) Felt you are in two or more different places at the same time? 43210

e) Felt that you do not have enough control over your responses and reactions? 43210

f) Felt apathetic, with no emotion? 43210

g) Felt as if you are almost two different people? 43210

\section{Appendix 2}

\section{Adapted GAIN Short Screener (A-GAIN-SS-20) for Internalizing, Externa- lizing, and Thought Disorder \\ GAIN Short Screener (GAIN-SS)(modified) \\ (Internalizing-Externalizing- substance abuse-Psychoticism)}

The following questions are about common psychological, behavioral, and personal problems. These problems are considered significant when you have them for two or more weeks when they keep coming back, when they stop you from meeting your responsibilities, or when they make you feel like you can't go on.

After each of the following questions, please tell us the last time, if ever, you had the problem by answering whether

- It was in the past week (5)

- It was in the past month (4),

- 2 to 3 months ago (3),

- 4 to 12 months ago (2),

- 1 or more years ago (1),

- Never (0).

A. When was the last time that you had significant problems with?

1) You spent a lot of time either getting alcohol or other drugs, using alcohol or other drugs, or recovering from the effects of alcohol or other drugs (e.g., feeling sick) 543210

2) Your use of alcohol or other drugs caused you to give up or reduce your involvement in activities at work, school, home, or social events? 543210

3) You kept using alcohol or other drugs even though it was causing social problems, leading to fights, or getting you into trouble with other people 5432 10

4) You had withdrawal problems from alcohol or other drugs like shaky hands, throwing up, having trouble sitting still or sleeping, or you used any alcohol or other drugs to stop 543210 being sick or avoid withdrawal problems 


\section{0}

5) Were a bully or threatened other people. 543210

6) Thinking about hurting self, ending your life or committing suicide 5432 10

7) Took something from a store without paying for it? 543210

B. When was the last time that you had significant problems with?

8) Feeling very anxious, nervous, tense, scared, panicked, or like something bad was going to happen 543210

9) Sleep trouble, such as bad dreams, sleeping restlessly, or falling asleep during the day 543210

10) Becoming very distressed and upset when something reminded you of the past 543210

11) Trying to avoid reminders of painful past events 543210

12) Feeling very trapped, lonely, sad, blue, depressed, or hopeless about the future 543210

13) Having unexpected or disturbing memories 543210

C. When was the last time that you?

14) Felt as if you are almost two different people? 543210

15) Felt that you do not have enough control over your responses and reactions 543210

16) Felt apathetic, with no emotion 543210

17) Felt people/enemies are following you any place you go 543210

18) Felt you are in two or more different places in the same time 543210

19) Get irritated, to the extent you do not care about safety 543210

20) Seeing or hearing things that no one else could see or hear 543210 